\title{
Land Use Based Urban Vulnerability to Climate Change Assessment
}

\author{
Giedrius Kaveckis $^{\mathrm{a}}$, Benjamin Bechtel $^{\mathrm{b}}$ \\ ${ }^{a}$ Research Associate/PhD Candidate in Klimacampus, University of Hamburg, Institute of Geography, Bundesstrasse 55, 20146 Hamburg, Germany \\ ${ }^{b}$ Research Associate in Klimacampus, University of Hamburg, Institute of Geography, Bundesstrasse 55, 20146 Hamburg, Germany
}

\begin{abstract}
Urban environments are potentially threatened by changing climate, especially in form of heat and flash flood hazards. Therefore, there is an urgent need to assess future urban vulnerability to these phenomenons. Purpose of this research is to define heat and flash flood indicators, based on land use, cover and morphology ofurban environments. We enhanced a standard scheme of local climate zones with extended urban morphology, which plays a key role in urban heat island effect. As heat hazard indicator we defined number of days, with fixed threshold exceeded temperature. Meanwhile for flash flood hazard we selected Curve Number, which considers soil type, hydrologic condition, land use, cover and percentage of impervious surface. Both of these indicators can be related to discrete urban classes and be ranked by hazard severity. Further step is to model future urban environment withrelation of heat and flash flood hazards, which eventually will be incorporated into future urban vulnerability framework.
\end{abstract}

Keywords: vulnerability; local climate zones; land use modeling; urban heat island; flash flood; heat wave; urban climate.

\section{Introduction}

Despite ongoing research on climate change, understanding of future climatic impacts to the population and their urban environments is still limited. One of the reasons is complexity of involved processes, such as change of climate, urban environment and social properties of the people, living within this environment. These processes were analyzed in many studies before, but their combination is still a major questionfor scientists. The big challenge is shortage of future data (projections), modeling and methods of future urban vulnerability assessment.

One of the most important climate change vulnerability factors is exposition (aka exposure) [1] - changing environment. In urban areas this process is even more actual. Throughout history, with increase of population, the number and size of urban areas expanded dramatically. According United Nations, today more than $52 \%$ of the world's population lives within cities and until 2050 this number will rise to an estimated 67\% [2]. This shows growing importance of urban areas and challenges facing people living within.

However, in case of extreme climatic impact, higher concentration of population would lead to higher human and property losses. One of the most relevant causes (about 95\%) of human losses inflicting natural disaster in post-industrial countries are heat waves [3], [4]. A heat wave is a period of unusually hot weather. In urban areas heat can even be intensified by a relatively warmer local climate called Urban Heat Island (UHI) [1].Most vulnerable groups towards heat are people with heart diseases, children and elderly (over age of 65). In 2003 was the hottest summer in Europe since 1500. According to some studies, about 15000 persons died due to the heat wave merely in France. Most of the victims were elderly [3], [5].

Another relevant hazard in urban areas is flash flood. Floods in general are most common and most property damage inflicting environmental hazard [4], [6]. Although different flood types exist (i.e. fluvial, pluvial, coastal), however, the focus of this project is pluvial (flash) flooding. The word "flash" representsimmediate occurrence, often without a warning. Main reasons are heavy rainfall and limited water drainage capabilities. Urban areas lack pervious surfaces where the water could seep away. This causes rapid runoff and sometimes causalities. Flash flood inflicted loss of 139 people in July 1976 , in Big Thompson Canyon, Colorado, USA. They drowned after $300 \mathrm{~mm}$ of rain in less than 6 hours. Most common victims of flash floods are people with limited mobility: diseased, elderly and children [4].

Corresponding author: Giedrius Kaveckis. E-mail address: giedrius.kaveckis@uni-hamburg.de http://dx.doi.org/10.3846/enviro.2014.122

(C) 2014 The Authors. Published by VGTU Press. This is an open-access article distributed under the terms of the Creative Commons Attribution License, which permits unrestricted use, distribution, and reproduction in any medium, provided the original author and source are credited. 
Main goal of our project is to assess future urban vulnerability of population to heat waves and flash floods in the Hamburg Metropolitan area. Vulnerability assessment involves projection of future urban environment, social composition of people living and possible impact of hazards within these zones. For projection of urban development large variety of forms, materials and structures has to be discretized according to specific physical properties, relevant for certain application. In future vulnerability assessment this is especially challenging since the future exposition towards heat and flash floods mainly depends on physical properties (land cover) while the urban development itself is rather driven by the demand for certain functions. Hence, the typology of urban classes must consolidate both approaches. Local Climate Zones (LCZ) scheme, which was introduced by Stewart \& Oke [7], is an examples of such classification, especially designed for UHI observational studies. LCZ take into account such factors as land use, morphology and surface cover.

Meanwhile this paper represents only a hazard part - the analysis of relations between heat waves, flash floods and different local climatic zones. We assume that specific hazard (extreme climatic impact) severity and the population susceptibility is related with certain LCZ. Therefore, our objective is to model future urban environment using land use modeling tool, relate and rank it to specific hazard severity and social-economic properties. Afterwards we attempt to integrate these three components into the future urban vulnerability assessment framework.

Specifically, the following questions shall be answered in this paper:

- What means vulnerability in context of climate change?

- How land use change can be related to vulnerability?

- What are requirements for LCZ scheme?

- How land use modeling tools can support future vulnerability assessment?

- What are hazards' indicators?

\section{Vulnerability}

Today term "vulnerability" is common in such fields like disaster and risk assessment, climate change and development. However, there is no single 'best' vulnerability, which would suit for any situation [8], [9]. Each situation is unique and should be assessed, before the vulnerability would be named. According Füssel [9] each situation should be considered by following factors (in brackets are factors, defined for our case study): temporal reference (future, 2050), scale (cross-scale, aka internal and external), disciplinary domain (integrated, aka biophysical and socio-economic), vulnerable system (Metropolitan area of Hamburg), attributed value (urban population), hazard (UHI and flash flooding). Afterwards, when these factors are known, the vulnerability of a certain situation can be described. And more we know, more detailed description to vulnerability can be given.

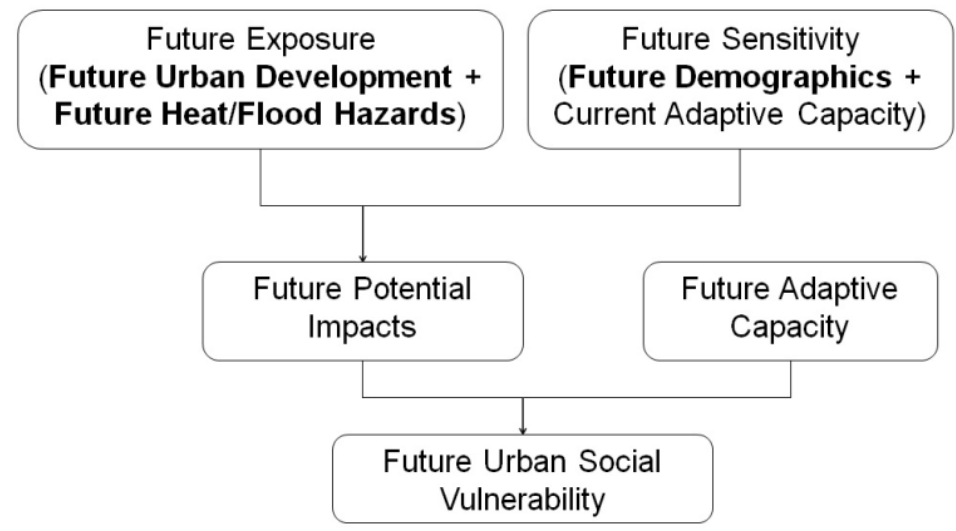

Fig. 1. Adapted conceptual IPCC framework for future urban social vulnerability assessment [11], after [12]

From numerous definitions of vulnerability we selected one, defined by Intergovernmental Panel for Climate Change (IPCC) [10] as the most detailed in order to identify a vulnerable situation. IPCC describes vulnerability as "the degree to which a system is susceptible to, or unable to cope with, adverse effects of climate change, including climate variability and extremes. Vulnerability is a functionof thecharacter, magnitude, and rate of climate variationto which a system is exposed, its sensitivity, and its adaptive capacity". This definition clearly identifies the system and its degree of susceptibility or inability to cope as vulnerability and gives clear view of the conceptual climate change representation of vulnerability (Fig. 1).

Although, the concept of vulnerability assessment framework is developed, due to the early phase of our research, the details of further steps still have to be analyzed. However, the main elements are known (Fig. 1). Sensitivity "is a degree to which a system is affected" [10]. Sensitivity in our project represents social and economic composition of people, based on how sensitive they are towards certain hazards. Similar properties determine another element - adaptive capacity. IPCC sees adaptive capacity as ability of a system to adjust to extremes, take advantage of opportunities and cope with consequences. Difference is that adaptive capacity is applied after the impact. It indicates how the system can deal with a stressor afterwards and come back to the primary state. However, in many situations it is hard to distinguish these two elements, due 
to their qualitative factors. The last element - exposition (aka exposure), is "a nature and degree to which a system is exposed to significant climatic variations". This term fully compromises with our suggested factors of exposure- future urban development and future heat/flood hazards.

In this paper we place higher emphasis especially on exposure, where the future urban development and the severity of our selected hazards could occur.

\section{Urban heterogeneity}

The earth's surface is very heterogenic. Main reasons are natural processes and human activity, like urban development, agriculture expansion, deforestation etc. Diversity between land can be represented by its cover, use and morphology. Higher diversity is noticeable especially in urban areas. They contain different types of buildings and surfaces with limited space, unique radiative, thermal, aerodynamic and moisture properties, which affects the severity of UHI [13]. These properties can be aggregated by land use and land cover. However, terms are often confused. Land cover is "observed physical and biological cover or the earth's land as vegetation or man-made features". Meanwhile land use is "the total of arrangements, activities, and inputs that people undertake in a certain land cover type" [14], [15]. For our project this is not an issue, cause the properties of use, cover and morphology are aggregated into the LCZ.

\subsection{Land use change}

While the local climate and flood susceptibility are mostly determined by the land cover and the urban development is driven by the demand for certain functions. Hence, change of land use can be understood as landscape transformation by human activities - link between human and natural systems. Land use may affect the climate and climate change will influence future land use. Outcome of land use practices is generally the same - to acquire natural resources for human needs and development. [1], [16]. Therefore these processes confirm that land use change represent human activity, which is important for vulnerability assessment.

\subsection{Urban morphology}

Nonetheless, in order to assess heat waves in urban areas, a strong emphasis must be placed on urban morphology. Urban morphology represents forms (geometry) of urban settlements and their patterns. Oke [17] differentiated two layers of the atmosphere in urban areas - Urban Canopy Layer (UCL) and Urban Boundary Layer (UBL). UCL (micro-scale, ground to roof level) consists of air between buildings. Energy exchange and airflow is very local. Climate is dominated by surroundings, especially materials and geometry. Meanwhile UBL (above roof level) is above UCL and is affected by urban land use, pollution, wind direction and its lower boundary.

Physical form and size of the buildingsaffect the wind, which ventilates urban area and decreases impact of the UHI. According Oke et al. [18] geometry may have such high effect on UHI as thermal admittance. Its most influencing factors are morphology, together with land use and land cover. UHI is the relatively warm place, comparing urban with surrounding rural areas[1]. However, the terms "rural" and "urban" are still not clear. None of them has a climatological relevance. Gugler [19] suggests that urban theorists identify today threshold between urban and rural as artificial, which is dynamic, rather than as dichotomy. And another problem exists, that variability of today's cities cannot be represented by two classesurban and rural. Therefore, a more comprehensive classification is essential. One of the way to represent diversity of the city and local climatic conditions is to class itby LCZ.

\subsection{Local Climate Zones (LCZ)}

First climatic based classification of the city was developed Chandler [20], who analyzed urban heat islands and separated London into four regions and distinguished each by its climate, physiography and built form. Today much more comprehensive representation is needed. Concept of LCZ as a classification scheme was developed by Stewart and Oke [7]. "Local" represents the scale, "climatic" - nature and "zonal" - the spatial distribution. In general, there are 17 LCZ. They are defined as regions by homogeneity of their environment and such factors as surface cover, human activity, material, and structure. Physical properties of each zone are measurable and do not depend on place or time. This classification standardizes urban and rural sites for temperature observations according unique combination of structure (building/tree height and spacing) and cover. However, we assume that LCZ classification can be used to measure also other phenomenaflash floods, based on such geometric and surface cover properties such as building surface fraction, impervious and previous surface fraction, height of roughness elements and terrain roughness class. Therefore, the further analysis of individual LCZ properties, which affects UHI and flash flooding impact, is important. 
However, Stewart's classification is typical for American, but does not fully represent the morphology of buildings blocks for the European cities. Therefore, we extended their scheme with the morphological structures from the German energetic district planning [21] (Fig. 2). Now each class contains more detailed morphological, use and cover description. This helps us to differentiate LCZ into subclasses with different properties and more accurately identify impacts of hazards.
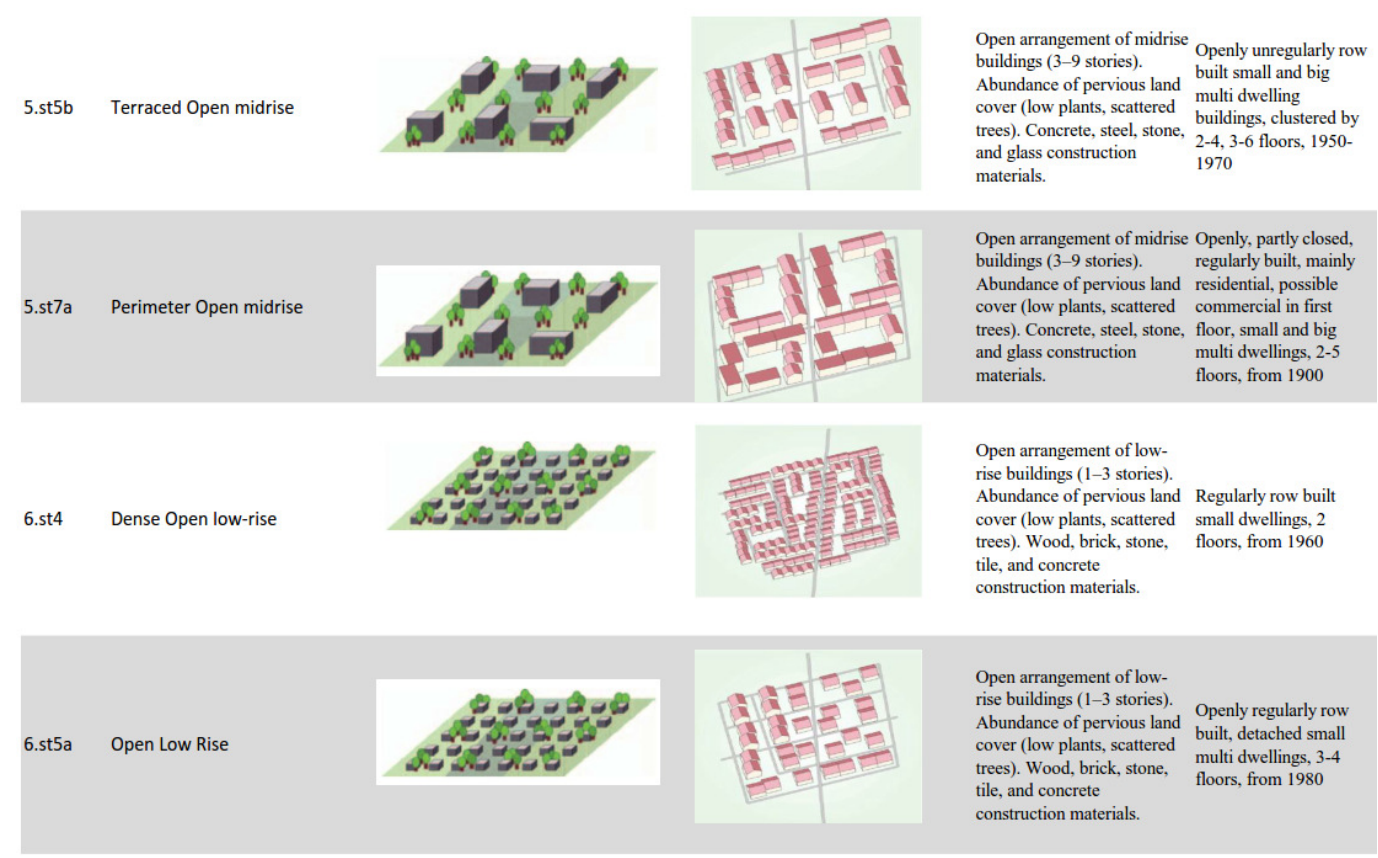

Fig. 2: Fragment of enhanced LCZ scheme (3rd and 5th columns are values from Stewart and Oke [7]), which includes the morphology from the German energetic district planning [21] (4th and 6th columns). First and second columns representabbreviation and name of the zone

\section{Land use modeling}

Modeling of land use can help to understand various urbanization processes and give possibility to the policymakers to explore conditions under different scenarios. Therefore, land use change models can be defined as decision support tool of the causes and consequences of land use change [22]. For our case study in Metropolitan Region of Hamburg we decided to use Metronamica, a raster based land use model, which uses Cellular Automata (CA).

\subsection{Cellular Automata}

CA is mathematical idealization of physical systems, where space and time are discrete [23]. Originally, CA was introduced by von Neumann in 1963. At that time it was named as "cellular spaces", which represented model of biological selfreproduction [24]. Every cell maintains a certain state (or function), which depends on the surrounding (neighborhood) cells. CA changes in a discrete time steps to the value which is affected by the site (cell) in its neighborhood. The value at each cell are updated synchronously, based on the neighboring cells and defined rules of the CA [23]. First time the CA was referred to geographical models in 1979 by Tobler [25]. It was able to represent realistic geographical processes and level of detail. Interaction of a location with surroundings is an important factor of the land use change [22], [26]. Such structures simulate dynamics that characterize city's growth and development [27].

\subsection{Metronamica}

Metronamica is a Spatial Decision Support System (SDSS) based on CA and developed by the company RIKS from Netherlands. Main applicable fields are urban and regional planning. Metronamica models dynamic future land use changes according various external factors, environmental constraints and land use policies. It also includes regional migration and transport model, which can simulate the jobs, population, migration between the regions and infrastructure's development effects on growing cities. Metronamica is calibrated on historical land use changes. After adjustment of factors, user can model future land use. Modeling enables planners to experiment and explore the effects of various scenarios, policy options, and their alternatives, to analyze possible socio-economic and physical processes, and their importance to the development of the city [28].

Modeling area in Metronamica is represented as a mosaic of grid cells. Each cell is occupied with a specific land use and all together constitute the land use pattern of the study area. By following the transition rules, each cell have a relative 
attractiveness to particular spatial agent. This cause change of land use from one to another. Changes of land use at local scale are driven by main four factors:

- Suitability - physical suitability defines the degree to which the particular land use cell can overcome other land use cell. This process is based on physical characteristics of the location, such as slope, soil type etc.

- Zoning - institutional suitability which impose spatial restrictions on allocation of the land use. Various zoning plans can be integrated and applied for specified time frame. One of the examples could be the prohibition of industrial development in low density residential area.

- Accessibility represents a function of transportation and is based on infrastructure network. Particular segments of infrastructure have different attractiveness to specific land use. For instance, the attractiveness of high density residential land use to underground metro stations is much higher than agriculture.

- Dynamic interaction of land use is a neighborhood potential of surrounding location. It has the highest influence of land allocation among other factors in Metronamica. Set of interaction rules defines a degree to which other land uses are attracted or repelled to the specific location by 8 cell radius. Real life representation would be the attractiveness of industry land use nearby the port areas or residential near urban green and parks [28].

During model's set up process these factors are applied in model. After model calibration using historical data, it is able to model land use under certain circumstances and scenarios.

\section{Hazard ranking}

\subsection{Overheating}

A future heat hazard indicator must fulfill a number of requirements. Firstly, for projections it must be based on the discretized land-use classifications. Secondly, it should be 'physically' meaningful, which means it should be related to the urban canopy layer air temperature or even better a bioclimatological index like PET or UTCI [29]. On the other hand, it should not suggest being an exact projection, which is not possible with the limited methodology. Eventually, the rank of different zones is more important than the absolute accuracy, since the exposure is likely to be normalized in the further vulnerability assessment.

As a quick approach a heat hazard indicator could be generated by the climatic impact of different LCZ as reported in previous studies. This could be complemented by the analysis of observations from different station nets from Hamburg as well as mobile measurements conducted with busses [30] which were collected in the Hamburg Urban Climate Database. This data could be integrated to an empirical UHI model for Hamburg and would also allow differentiating the urban heat island effect for different times of days and synoptic conditions and such consider the future change of weather patterns.

The indicator should allow evaluation of different climate change scenarios. Therefore, the number of days where the temperature exceeds a fixed threshold seems a suitable indicator. For instance the frequency distribution of future temperatures will be combined with a mean nocturnal signal of a specific urban class to derive the spatially differentiated number of tropical nights. This would be meaningful but not too sophisticated and thus seems a good compromise in terms of the above mentioned criteria.

However, a general limitation is that no land use based approach accounts for the inner-class variability which also can be substantial according to first results. Also the response of the each LCZ towards specific meteorological conditions is assumed to stay constant. This neglects that the material within the classes and its physical properties are also changing in time (for instance energy-saving renovation which is an important mitigation measure will also influence the heat storage in buildings and possibly the albedo and net radiation). To account also for such changes within the classes, microscale model could be used to evaluate the response of the LCZ in heat waves, which however are limited by computing time.

\subsection{Flash flood}

A future flash flood indicator, same as heat hazard, should be based on land use classifications and physical interpretation. It should be associated with the surface's and soil's properties of the urban canopy level and would rank LCZ by their susceptibility to flash flood.

Flash flood is not typical flood, which is caused by rising water in river or stream. Typical flood may last days or weeks. Meanwhile the often cause of flash flood is heavy precipitation in a short period of time (less than 6 hours). Other cause can be a break of dam or levee (dike) [31] (this cause is not considered in this research). Flash flood can be very local, depending on precipitation. Meanwhile regular flood is more prominent to the areas close to natural water sources and water ways. A common cause for both of them is the same - precipitation (climatological forces) and surplus of water. However, there exist secondary, the flood intensifying conditions. Those are related to hydraulic geometry of basin and depend on environment [4]. Due to our focus on relative hazard susceptibility on cell basis, the complex hydraulic modeling considering geomorphology is very limited. Therefore, we take into account factors, which are related to different LCZ. One of such factors is infiltration. Urbanization increases the creation of highly impermeable surfaces, such as paved yards, roofs, roads and parking lots. This inhibits infiltration of precipitation, decreases water travel time and a high proportion of storm rainfall appears as direct runoff [32]. Higher runoff causes higher severity of flash flood. 
Although infiltration values of LCZ are unknown, but they can be derived from such properties as building surface and land zones impervious surface fraction. One of the appropriate methods to identify direct runoff or infiltration in small (especially in urbanized) catchments, is the curve number $(\mathrm{CN})$ method, developed by United States Natural Resources Conservation Service (NRCS). CN is an empirical parameter, which converts rainfall to runoff. This parameter is based on soils, plant cover, amount of impervious areas, surface water storage and interception. Actually, the value of CN is percentage expression and determines the proportion of how much rainfall appears as direct runoff (Fig. 3). For instance, $\mathrm{CN}$ with value of 100 means that all rainfall appears as direct runoff and no water infiltrates the ground.

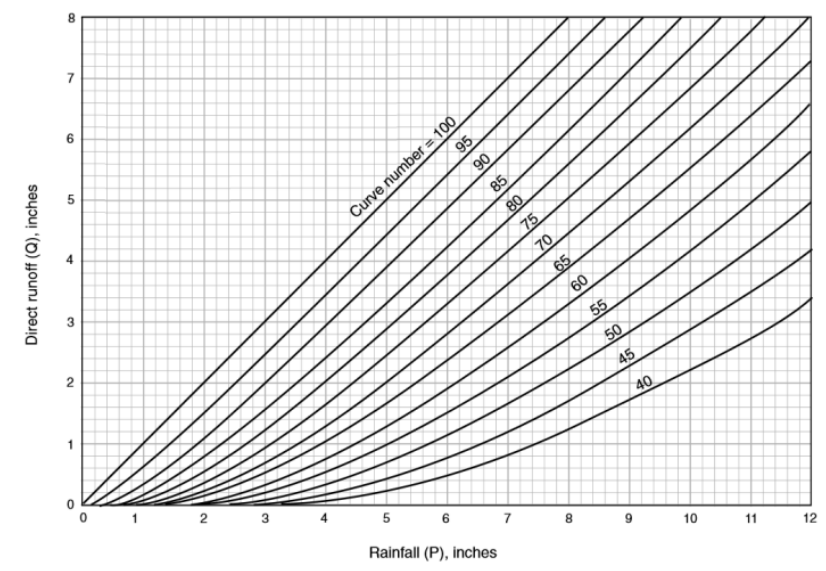

Fig. 3: Visualization of rainfall appearance as direct runoff based on $\mathrm{CN}$ value [33]

NRCS developed a methodology to identify $\mathrm{CN}$ for each land use/cover zone, based on soil, \% of impervious area and hydrologic condition [33]. Many studies exist where this methodology was successfully applied outside the United States. Therefore our further step will be to develop CN values for each LCZ, based on their physical properties and afterwards rank them according the flood hazard susceptibility. Results will be considered in vulnerability assessment.

\section{Discussion}

General problem of vulnerability assessment is that no common and clear framework exists. A reason is that each vulnerable situation is unique and requires different methods to assess it. However, it is even more complicated to identify future vulnerability, because the complexity is not limited only by available frameworks, but also by lack of data or uncertainty, emerged from future modeled data, if available.

Other issue is the representation of environment as discrete classes. Interpretation can vary a lot: what is land use if the first floor is used for shops and the second for living apartments; is this area vegetated enough to be called urban green; is the space between the buildings big enough to call it open midrise; and many other instances. Further, inner-class variability and changes of physical properties during time are important. However, these issues are too complex to assess and model.

And when it comes to the future modeling it is even more complex. Nonetheless, land use modeling does not predict future, but explores and helps to understand decisions, which could change it. Common practice is to develop certain scenarios, model them and analyze possible consequences. Task of such models is to support decision makers, but not to make decisions.

\section{Conclusions}

In order to model and assess future urban vulnerability to climate change we placed much emphasis on exposition, which represents urban environment in our project. Heat and flash flood hazard were considered as most potential impacts of climate change. However, due to complexity of these hazards, the standard definition of LCZ was not sufficient. Therefore we enhanced it is by combining extended urban morphology features. We developed a method, how land use, cover and morphology can be related to the severity of UHI and flash flooding hazards, based on empirical analysis. For UHI analysis we selected the number of days, where temperature exceeds fixed threshold as an indicator. Meanwhile indicator for flash flooding the Curve Number, which represents hydrologic condition, soil type, land use, cover type and percentage of impervious surface, was endorsed. Our next task is to input our enhanced LCZ scheme into Metronamica and model future LCZ together with possible hazard impact, which will serve as exposition in our future urban vulnerability assessment framework.

\section{Acknowledgements}

This research was undertaken as part of the project, supported through the Cluster of Excellence 'CLISAP' (EXC177), University of Hamburg, funded through the German Science Foundation (DRG). 


\section{References}

[1] Susan, S. 2007. Climate change 2007-the physical science basis. Working group I contribution to the fourth assessment report of the IPCC, Cambridge University Press.

[2] United Nations Department of Economic and Social Affairs, Population Division, 2011. "World Urbanization Prospects, the 2011 Revision" [Online]. Available from Internet: http://esa.un.org/unup/CD-ROM/Urban-Rural-Population.htm. [Accessed: 13-Jan-2014].

[3] Poumadère, M.; Mays, C.; Le Mer, S. and Blong, R. 2005. The 2003 heat wave in France: dangerous climate change here and now, Risk Anal. Off. Publ. Soc. Risk Anal. 25(6): 1483-1494. http://dx.doi.org/10.1111/j.1539-6924.2005.00694.x

[4] Smith, K. 1992. Environmental hazards: assessing risk and reducing disaster. Routledge, London; New York.

[5] Assemblee Nationale, 2004, "N 1455 - 01 - Rapport de la commission d'enquête sur les conséquences de la canicule (MM. Claude Evin, François d'Aubert) (tome I)" [Online]. Available from Intenet: http://www.assemblee-nationale.fr/12/rap-enq/r1455-t1 asp. [Accessed: 21-Jan-2014].

[6] Centre for Research on the Epidemiology of Disasters - CRED. 2012. "Database | EM-DAT".

[7] Stewart, I. D. 2011. Redefining the urban heat island. PhD Dissertation.

[8] Green, C. 2004. The evaluation of vulnerability to flooding, Disaster Prev. Manag. 13(4): 323-329. http://dx.doi.org/10.1108/09653560410556546

[9] Füssel, H. M. and Klein, R. J. T. 2006. Climate Change Vulnerability Assessments: An Evolution of Conceptual Thinking, Clim. Change 75(3): 301329. http://dx.doi.org/10.1007/s10584-006-0329-3

[10] McCarthy, J. J. 2001. Climate change 2001: impacts, adaptation, and vulnerability: contribution of Working Group II to the third assessment report of the Intergovernmental Panel on Climate Change. Cambridge University Press.

[11] Kaveckis, G.; Daneke, C.; Bechtel, B. and Oßenbrügge, J. 2013. Conceptual framework for future urban social vulnerability assessment, in Poster, GIForum 2013, Salzburg, Austria.

[12] Isoard, S. 2010. Perspectives on Adaptation to Climate Change in Europe. p. 51-68

[13] Oke, T. R.; Crowther, J. M.; McNaughton, K. G.; Monteith, J. L. and Gardiner, B. 1989. The micrometeorology of the urban forest [and discussion], Philos. Trans. R. Soc. Lond. B Biol. Sci. 324(1223): 335-349. http://dx.doi.org/10.1098/rstb.1989.0051

[14] Food and Agriculture Organization of the United Nations ( FAO). 1999. "Terminology for Integrated Resources Planning and Management," Food Agric. Organ. Nations Environ. Programme Rome Italy, Nairobi Kenia.

[15] Food and Agriculture Organization of the United Nations (FAO). 1999. State of the World's Forests 1999, FAO, Rome.

[16] Foley, J. A.; DeFries, R.; Asner, G. P.; Barford, C.; Bonan, G.; Carpenter, S. R.; Chapin, F. S.; Coe, M. T.; Daily, G. C. and Gibbs, H. K. 2005. Global consequences of land use, Science 309(5734): 570-574. http://dx.doi.org/10.1126/science.1111772

[17] Oke, T. R. 1976. The distinction between canopy and boundary-layer urban heat islands, Atmosphere 14(4): 268-277.

[18] Oke, T. R.; Johnson, G. T.; Steyn, D. G. and Watson, I. D. 1991. Simulation of surface urban heat islands under 'ideal' conditions at night part 2: Diagnosis of causation, Bound.-Layer Meteorol. 56(4): 339-358. http://dx.doi.org/10.1007/BF00119211

[19] Gugler, J. 1996. The Urban transformation of the developing world. Oxford University Press, Oxford.

[20] Oke, T. R. 2009. Chandler, T. J. 1965: The climate of London, Prog. Phys. Geogr. 33(3): 437-442. http://dx.doi.org/10.1177/0309133309339794

[21] Erhorn-Kluttig, H.; Jank, R.; Schrempf, L.; Dütz, A.; Rumpel, F.; Schrade, J.; Erhorn, H.; Beier, C.; Sager, C. and Schmidt, D. 2011. Energetische Quartiersplanung. Fraunhofer IRB Verlag, Stuttgart.

[22] Verburg, P. H.; Schot, P. P.; Dijst, M. J. and Veldkamp A. 2004. Land use change modelling: current practice and research priorities, GeoJournal 61(4): 309-324. http://dx.doi.org/10.1007/s10708-004-4946-y

[23] Wolfram, S. 1983. Statistical mechanics of cellular automata, Rev. Mod. Phys. 55(3): 601. http://dx.doi.org/10.1103/RevModPhys.55.601

[24] Von Neumann, J. 1951. The general and logical theory of automata, Cereb. Mech. Behav., 1-41.

[25] Tobler, W. R. 1979. Cellular geography, Philosophy in geography, Springer, 379-386.

[26] Torrens, P. M. and O'Sullivan, D. 2000. Cities, cells, and complexity: developing a research agenda for urban geocomputation,in 5th international conference on GeoComputation, University of Greenwich, UK.

[27] Batty, M. 2007. Cities and complexity: understanding cities with cellular automata, agent-based models, and fractals. The MIT press.

[28] Research Institute for Knowledge Systems (RIKS BV). 2012. "Metronamica Documentation."

[29] Jendritzky, G.; Dear, R. and Havenith, G. 2012. UTCI-Why another thermal index?, Int. J. Biometeorol. 56(3): 421-428. http://dx.doi.org/10.1007/s00484-011-0513-7

[30] Langkamp, T. 2013. Contributions towards a downscaling scheme for urban climate modeling integrating mobile measurements and improved roughness representation for Hamburg. (Germany).

[31] US Department of Commerce N., "Flood and flash flood definitions" [Online]. Available: http://www.srh.noaa.gov/mrx/hydro/flooddef.php. [Accessed: 27-Jan-2014].

[32] White, M. D. and Greer, K. A. 2006. The effects of watershed urbanization on the stream hydrology and riparian vegetation of Los Penasquitos Creek, California, Landsc. Urban Plan. 74(2): 125-138. http://dx.doi.org/10.1016/j.landurbplan.2004.11.015

[33] U.S. Soil Conservation Service. 1986. Technical Release 55: Urban Hydrology for Small Watersheds.” 